\title{
Duration of Second Stage of Labour and Maternal Outcome
}

\author{
Husnia Hussen, Shiferaw Negash, Yitbarek Fantahun and Lukman Yusuf* \\ Department of Obstetrics and Gynecology, College of Health Sciences, School of Medicine, Addis Ababa University
}

*Corresponding author: Lukman Yusuf, Department of Obstetrics and Gynecology, College of Health Sciences, School of Medicine,

Addis Ababa University

\begin{tabular}{|c|}
\hline ARTICLE INFO \\
\hline Received: 蔧 October 01, 2019 \\
\hline Published: October 15, 2019 \\
\hline $\begin{array}{l}\text { Citation: Husnia Hussen, Shiferaw Ne- } \\
\text { gash, Yitbarek Fantahun, Lukman Yusuf. } \\
\text { Duration of Second Stage of Labour and } \\
\text { Maternal Outcome. Biomed J Sci \& Tech } \\
\text { Res 22(1)-2019. BJSTR. MS.ID.003683. }\end{array}$ \\
\hline
\end{tabular}

Keywords: Maternal Outcome; Second Stage; Labour; Addis Ababa Ethiopia

\begin{abstract}
Background: The second stage of labour begins from full dilatation of the cervix up to the birth of the singleton baby or the last baby in a multiple pregnancy entailing a process of descent, rotation and expulsive or propulsive efforts. The ideal management of the second stage should maximize the probability of vaginal delivery while minimizing the risks of maternal morbidity and mortality.
\end{abstract}

Objective: The main objective of this study is to determine the relationship between the duration of the second stage of labour and adverse maternal outcomes.

Methods: Facility based prospective cohort study design was employed on women who delivered in four teaching hospitals from January 1 to July 30, 2018. The study population are mothers with term, post term, cephalic, live, singleton pregnancies who had either spontaneous onset of labour or whose labour was induced and delivered during the study period. Accordingly, a total of 3776 mothers who fulfilled the inclusion criteria were included in the study. Mean with standard deviation for quantitative variable, percentage and proportion for qualitative variable was analysed. Odds ratio with 95\% confidence interval was applied to measure association. Regression analysis was used where necessary to see the association between dependent and independent variables.

Result: The mean age of the participants was $26.4+4.5$ years. The mean duration of SSOL is $62 \mathrm{~min} \pm 44(4-330 \mathrm{~min})$. It significantly dropped with an increasing age of the mothers $(<0.013$ and $\mathrm{P}<0.001$, respectively). The rate of vaginal delivery dipped progressively with prolonged SSOL beyond $1 \mathrm{hr}$. The composite maternal complications increased with a protracted duration of second stage of labour $(\mathrm{P}<0.001)$. After controlling for the confounders, operative delivery is independently associated with increasing duration of SSOL $(\mathrm{P}<0.001, \mathrm{aOR}=1.019,95 \% \mathrm{CI}=1.017-1.021)$. In general, major degree perineal tear, $\mathrm{PPH}$, uterine atony, estimated blood loss of $>500 \mathrm{ml}$ had a statistically significant association with prolonged second stage of labour $(\mathrm{P}<0.001)$.

Conclusion: Overall, we observed that when the second stage of labour progressed beyond1hour, there remained a relatively high probability of achieving vaginal delivery. However, these women are much more likely to undergo operative vaginal delivery, are at higher risk of postpartum haemorrhage, have higher risks of perineal trauma and have increased caesarean section rate. Labour should be re-assessed to avoid poor maternal outcomes if a second stage of labour lasts for more than an hour.

\section{Introduction}

The conventional 2-hour rule of the second stage of labour dates to the 1800's and is defined as the period between full cervical dilatation of $10 \mathrm{~cm}$ and the birth of the baby [1-4]. In doing so, there is constant descent of the presenting part along with the processes of flexion and rotation in conformity to the shape of the pelvic passage culminating with the woman's involuntary urge to 
bear down as a result of increased intra-abdominal pressure and expulsive uterine contractions and finally giving birth. Abnormal labour is more associated with a conundrum of semantic issues (abnormal labour, dystocia, protraction disorder, arrest disorder) implying failure to progress and an abnormally long latent phase or second stage that is described as prolonged deviating from the usual description of normal labour. Although labour is regarded as a physiological phenomenon, there is a tremendous work output, energy expenditure, fluid and electrolyte imbalances and physical exhaustion as well as alterations in the psyche of the parturient.

The epidemiology of the length of labour was reported by Friedman in several landmark articles over 60 years ago that are very much respectfully and academically accepted to date [2,3]. These studies changed modern obstetrics; most specifically, they led to specific normative guidelines on the length of the first and second stages of labour. It is very recently that the ACOG had modified and defined prolonged second stage in nulliparous patients as a lack of continuing progress for 3 hours with regional anaesthesia or 2 hours without regional anaesthesia; for multiparous patients, a lack of progress for 2 hours with or 1 hour without regional anaesthesia [4]. It is recommended by the WHO that the women should be informed of the reality that the duration of the second stage varies from one woman to another and in that in the first labours, birth is usually completed within 3 hours whereas in subsequent labours, birth is usually effected within 2 hours [5].

The clinical practice dictates that as the duration of second stage of labour increases, there are likelihoods to encounter increased risk of a multitude of maternal and neonatal morbidity [6-9]. Retrospective chart reviews and cohort studies demonstrated that there exist a possibility of difficult cesarean sections andinstrumental vaginal deliveries with resultant maternal morbidities like postpartum haemorrhage, uterine atony, severe obstetric lacerations, chorioamnionitis, puerperal sepsis and third or fourth-degree perineal lacerations with most prolonged second stages of labour [4,10-15]. The second stage of labor is regarded as the climax of the birth by the delivering woman, her partner, and the care provider [16]. It has been thought of as a time of particular asphyxial risk for the fetus and maternal morbidity. The perceived risks have been invoked to justify arbitrary time limits and high rates of interferences including operative vaginal and abdominal deliveries $[10,17,18]$. The second stage of labor is often regarded as a time when mother and obstetrician are physically and mentally exhausted and there is a great temptation to "do something" to end the labor [17]. There is no study done in Ethiopia that evaluated the effect of duration of second stage of labour on maternal outcome. Thus, the study will shade light into this important issue, serve as a reference and contribute to a much larger scale of nationwide undertakings. We would like to bring forth our intention of treating perinatal outcome separately in the light of the bulky nature of the study and avoid undue congestion of data.

\section{Materials and Methods}

This facility-based prospective cohort study of women in labour who reached second stage was conducted in four teaching government hospitals in Addis Ababa from January 1 to July 30, 21019. The four teaching hospitals are Tikur Anbesa Specialized Hospital (TASH), Gandhi Memorial Hospital (GMH), Zewditu Memorial Hospital (ZMH) and Yekatit 12 Hospital (Y $12 \mathrm{H}$ ). It is to be noted that the institutions have ante partum, intra partum and postpartum services for obstetric patients. Their delivery wards have active pre-labour beds, second stage rooms, delivery couches and neonatal resuscitation rooms with radiant heater, oxygen and suction machine. They are invariably staffed by midwives, interns, residents and consultants. This cohort study design was employed on all women with pregnancy beyond 37 gestational weeks (term, post term, vertex) with live and singleton births who reached or otherwise were referred to in second stage of labour and delivered in the four teaching hospitals. All the parturient who did not fulfill these criteria including those with underlying medical complications warranting immediate delivery, who came from home or referring centers at second stage were excluded from the study.

The minimum cohort sample size was determined using Epiinfo stat-calc using, as a reference, an article by Yueh Chang Kuo and et al. [19]. A sample size of 1550 for the exposed and nonexposed each making for the total sample size of 3100 was initially calculated. Adding a $10 \%$ non- response rate of 310 for the total sample size, the sum was put at 3410 . We found it convenient and opted for more cases bringing up the final sample size to 3776 . The independent variables analyzed included socio-demographic characteristic, gravidity, parity, gestational age, birth weight, mode of delivery and antenatal complications (PROM, chorioamnionitis, hypertension, gestational diabetes, cesarean scar...) whereas the dependent variables of importance were maternal outcomes that included postpartum haemorrhage (estimated blood loss of $>500$ $\mathrm{ml}$ or $10 \%$ drop in haematocrit after delivery ), chorioamnionitis, perineal trauma (third- or fourth-degree lacerations), operative vaginal delivery and Cesarean delivery.

Mean with standard deviation for quantitative variable, percentage and proportion for qualitative variable was analyzed. To control the effect of confounding variables, stepwise multiple logistic regression analysis was carried out and Adjusted Odds Ratios (AORs) employed to explore the real association. A confidence limit of $95 \%$ and p-value less than 0.05 was used as cut of point to see presence of statistical significance. Chi square and Fisher exact test was also used for categorical variables. The maternal data were collected by the principal investigator and trained health care provider attending the procedure and other health professionals oriented about the data collection process. The duration of second stage of labour was determined based on the number in minutes from the first cervical examination that revealed full dilatation 
until the time of the delivery. Data cleaning was performed to check for outliers, missed values and any inconsistencies before the data were analyzed using the software. Ethical clearance was obtained from the Ethical Clearance Committee of the Department of Obstetrics and Gynaecology. Communication to the medical directors of each hospital was made through formal letter obtained from the Department. Participation was on voluntary basis and no remunerations were issued to anybody for any reason.

\section{Results}

A total of 3776 mothers who fulfilled the inclusion criteria were included in the study. Majority of them, 1606 (42.5\%) gave birth in Black Lion Hospital, the rest were in Yekatit 12, Gandhi Memorial, and Zewditu Memorial Hospitals, 794(21\%), 698(18.5\%), 678 $(18 \%)$ respectively. The mean age of the mothers was $26.4 \pm 4.5$ (14$45)$ with $3112(82.4 \%)$ of the population falling in the age range of 20-30 years. The median family income per month in ETB calculated at 3000 (200-47000). Almost all, 3682 (97.5\%) were from Addis Ababa and its environs, with Amharas 1552(41.1\%) and Oromos 933(24.7\%) making for the bulk of the study population. Orthodox Christianity 2186(57.9\%) and Islam 1167(30.9\%) constituted the main religious domains. Majority, 1809(47.9\%) were housewives followed by private employees $1174(31.1 \%)$. Most study subjects 2945(78\%) had above a primary level school education (Table 1).

Table 1: Sociodemographic characteristics of the mothers.

\begin{tabular}{|c|c|c|c|}
\hline Socio Status & Demographic & Number & Percent \\
\hline \multirow{2}{*}{ Address } & Addis Ababa & 3681 & 97.5 \\
\hline & Out of Addis Ababa & 95 & 2.5 \\
\hline \multirow{6}{*}{ Ethnicity } & Amhara & 1563 & 41.1 \\
\hline & Oromo & 931 & 24.7 \\
\hline & Gurage & 522 & 13.8 \\
\hline & Silte & 231 & 5.9 \\
\hline & Others & 231 & 6.1 \\
\hline & Married & 3639 & 96.4 \\
\hline \multirow{2}{*}{ Marital status } & Single & 120 & 3.2 \\
\hline & Widowed & 17 & 0.5 \\
\hline \multirow{5}{*}{ Religion } & Orthodox & 2185 & 57.9 \\
\hline & Muslim & 1165 & 30.9 \\
\hline & Protestant & 413 & 10.9 \\
\hline & Catholic & 9 & 0.2 \\
\hline & Others & 4 & 0.1 \\
\hline \multirow{7}{*}{ Occupation } & Housewife & 1809 & 47.9 \\
\hline & Government employee & 622 & 16.5 \\
\hline & Private employee & 1173 & 31.1 \\
\hline & Daily labourer & 128 & 3.4 \\
\hline & Students & 21 & 0.6 \\
\hline & Merchants & 19 & 0.5 \\
\hline & Others & 4 & 0.1 \\
\hline \multirow{5}{*}{ Educational Status } & Illiterate & 335 & 8.9 \\
\hline & Read and write & 494 & 13.1 \\
\hline & Primary school & 1046 & 27.7 \\
\hline & Secondary school & 1103 & 29.2 \\
\hline & College and above & 796 & 21.1 \\
\hline
\end{tabular}

Of the study population, 2897 (76.7\%) had ANC follow up at $\mathrm{HC}$ and were referred to hospitals for delivery for different reasons. The reason for referral was not clearly described in 2156(74.5\%) except for the statement "for better care" (Table 2). The mean GA was $40.14 \pm 1.52(37-43+6)$ weeks. The mean hematocrit level at admission was $39.06 \pm 3.3$ (21-51). The onset of labor was spontaneous in $3466(91.8 \%)$ of the study subjects, of which 139 (3.7) had their labor augmented. Whereas, $310(8.2 \%)$ of the mothers had their labor induced, the most common indications being; preeclampsia, post term, and PROM comprising 102(32.9\%), $95(30.6 \%)$, and $90(29 \%)$, respectively. The median duration of labor was 12.3 hours while the mean is $14.4 \pm 8.3$ (2-72hours). The mean duration of SSOL was put at $62 \mathrm{~min} \pm 44$ (4-330min). The mean duration of SSOL in nullipara was 69.4 \pm 47.4 (5-330) minutes, multipara 55.7 \pm 39.5 (4-288) minutes, and in grand multipara $52 \pm 32$ (10-130) minutes, the difference was statistically significant, $\mathrm{P}<0.001$. The mean duration of SSOL was significantly higher at $\mathrm{ZMH}$ than BLH, GMH, and Y12H, (83.8 versus 54.2 P<0.001), (83.8 versus 66.6 $\mathrm{P}<0.001$ ) (83.8 versus $59.4 \mathrm{P}<0.001$ ) respectively.

Table 2: Maternal outcomes of the mothers.

\begin{tabular}{|c|c|c|}
\hline Most common reasons Forreferral & Number & Percent \\
\hline Prolonged labour & 251 & 6.9 \\
\hline Postterm & 139 & 3.7 \\
\hline Hypertension & 106 & 2.8 \\
\hline PROM & 99 & 2.6 \\
\hline Non reassuring fetal status & 65 & 1.7 \\
\hline Better care & 2159 & 57.1 \\
\hline Hospital ANC & 879 & 23.2 \\
\hline Others & 78 & 2 \\
\hline Gravidity & Number & Percent \\
\hline $1^{\text {st }} 1615$ & & 42.8 \\
\hline $2^{\text {nd }} 1226$ & & 32.5 \\
\hline $3^{\text {rd }} 573$ & & 15.2 \\
\hline $4^{\text {th }} 220$ & & 5.8 \\
\hline$\geq 5^{\text {th }} 142$ & & 3.7 \\
\hline Parity & Number & Percent \\
\hline 0 & 1997 & 52.9 \\
\hline 1 & 1116 & 29.6 \\
\hline 2 & 423 & 11.2 \\
\hline 3 & 175 & 4.6 \\
\hline 4 & 31 & 0.8 \\
\hline$\geq 5$ & 34 & 0.9 \\
\hline Antepartum morbidity & Number & Percent \\
\hline PROM & 297 & 7.9 \\
\hline $\mathrm{HT}$ & 255 & 6.8 \\
\hline Previous c/s scar & 97 & 2.6 \\
\hline $\mathrm{APH}$ & 25 & 0.7 \\
\hline Diabetes & 19 & 0.5 \\
\hline Chorioamnionitis & 32 & 0.8 \\
\hline Others & 67 & 1.7 \\
\hline Mode of delivery & Number & Percent \\
\hline
\end{tabular}




\begin{tabular}{|c|c|c|}
\hline SVD & 3404 & 90.1 \\
\hline CS & 157 & 4.2 \\
\hline Forceps & 79 & 2.1 \\
\hline Vacuum & 136 & 3.6 \\
\hline Total & 3776 & 100.0 \\
\hline Duration of SSOL in minutes & Frequency & Percent \\
\hline$<30 \mathrm{~min}$ & 595 & 15.8 \\
\hline$<1 \mathrm{hr}$ & 2108 & 55.8 \\
\hline$<2 \mathrm{hr}$ & 3257 & 86.3 \\
\hline$<3 \mathrm{hr}$ & 3668 & 97.1 \\
\hline$<4 \mathrm{hr}$ & 3753 & 99.4 \\
\hline$\geq 4 \mathrm{hr}$ & 23 & 0.6 \\
\hline
\end{tabular}

As maternal age increased, duration of labor significantly decreased $(\mathrm{P}=0.013)$. It was also observed that as maternal age increased, the SSOL significantly dropped $(\mathrm{P}=0.001)$ as $53.1 \%$ of mothers $<20$ years old delivered within 1 hour whereas $63.8 \%$ of mothers aged $\geq 35$ years delivered within the same time limit. Maternal age and weight of the baby revealed a significant positive correlation $(\mathrm{P}<0.001)$ as much as a higher maternal income contributed to an increased weight of the baby significantly $(\mathrm{P}=0.003)$. The mean EBL is $251 \mathrm{ml} \pm 105(100 \mathrm{ml}-1500 \mathrm{ml})$. A total of $406(10.8 \%)$ mothers had one or more maternal complications. Of the total study subjects who had complications; $28(0.7 \%)$ had uterine atony, $10(0.3 \%)$ major degree perineal tear, $12(0.3 \%)$ of the mothers had pre and postpartum hematocrit difference of $\geq 10 \%$. $\mathrm{EBL}>500 \mathrm{ml}$ was found in 121(3.2\%) of the total studied subjects, the overall rate of PPH in the study population was $125(3.3 \%)$. As parity increased, hematocrit values of the mothers at admission registered at significantly the lower levels $(\mathrm{P}<0.001)$ compared to the low parity or nulipara. There was no significant association in antenatal morbidity with parity $(\mathrm{P}=0.905)$. As parity increased, duration of labor and duration of SSOL significantly decreased for both $(\mathrm{P}<0.001)$. As parity increased, it was shown that weight of the baby also significantly increased $(\mathrm{P}<0.001)$. There was statistically significant positive correlation between parity and maternal morbidity, as a higher parity resulted in increased maternal complication $(\mathrm{p}<0.001)$. There was statistically significant negative correlation between antenatal morbidity and GA at delivery
$(\mathrm{P}<0.001)$. Duration of labor and GA had a statistically significant positive correlation $(\mathrm{P}<0.001)$. However, duration of SSOL had no significant association with $\mathrm{GA}(\mathrm{P}=0.740)$. There was no significant association in maternal complication with $\mathrm{GA}(\mathrm{P}=0.146)$.

Those mothers who were induced had significantly shorter duration of labor than those whose labor started spontaneously $(\mathrm{P}<0.001)$. Those mothers who were induced demonstrated significantly shorter duration of SSOL than those whose labor started spontaneously ( $\mathrm{P}=0.009)$. Significantly more mothers having antenatal complications were induced compared to those with no antenatal complications ( $24.4 \%$ vs. $4.3 \%, \mathrm{P}<0.001)$. However, the composite maternal morbidity of those mothers who were induced was not significantly different from those who had spontaneous onset of labor $(\mathrm{P}=0.278)$. The mothers who were augmented had significantly longer duration of labor and SSOL than those who were not, $\mathrm{P}<0.001$ and 0.016 , respectively. There rate of maternal morbidity was significantly higher among those augmented than those who were not, $(24.3 \%$ versus $15.6 \%, \mathrm{P}=0.009$ and $21.4 \%$ versus $10.3 \%, \mathrm{P}<0.001$ ), respectively.

Duration of SSOL had a statistically significant negative correlation with income, gravidity and parity $(\mathrm{P}<0.001)$. The mean duration of SSOL was significantly longer in those mothers who had operative delivery compared to SVD $(107.4 \mathrm{~min}$ vs. 58.1min, $\mathrm{P}<0.001)$. After controlling for confounders, operative delivery was independently associated with increasing duration of SSOL $(\mathrm{P}<0.001, \mathrm{aOR}=1.019$ and $95 \% \mathrm{CI}=1.017$ to 1.021). Duration of SSOL and weight of the baby showed a statistically significant positive correlation $(\mathrm{P}=0.021)$. Vaginal delivery rate progressively decreased with increasing duration of SSOL beyond $2 \mathrm{hrs}$ and the difference was statistically significant. For those mothers who delivered within $1 \mathrm{hr}$ of SSOL the rate was $95.1 \%$ compared to $37.5 \%$ to those who delivered after 4-hours of SSOL $(\mathrm{P}<0.001)$ (Table 3). Uterine atony was significantly associated with mothers whose SSOL $\geq 4 \mathrm{hrs}$ compared to $\leq 1 \mathrm{hr}(8.3 \%$ vs. $0.5 \%, \mathrm{p}=0.002$, aOR $=15.0$ and $95 \% \mathrm{CI}$ is 2.7-81.8). Major degree tear was significantly higher and more frequently seen in mothers whose SSOL was $\geq 4 \mathrm{hrs}$ compared to $\leq 1 \mathrm{hr}(4.2 \%$ vs. $0.2 \%, \mathrm{P}=0.006$, aOR $=26.5$ and $95 \% \mathrm{CI}$ is $2.5-276)$. EBL had a statistically significant positive correlation with duration of SSOL $(\mathrm{P}<0.001)$.

Table 3: Delivery mode with increasing duration of SSOL.

\begin{tabular}{|c|c|c|c|c|c|c|c|c|c|}
\hline & \multicolumn{3}{|c|}{ Delivery (\%) } & \multicolumn{3}{|c|}{ Delivery (\%) } & \multicolumn{3}{|c|}{ Delivery (\%) } \\
\hline & $\leq 1 \mathrm{hr}$ & $\geq 2 \mathrm{hr}$ & P-value & $<1 \mathrm{hr}$ & $\geq 3 \mathrm{hr}$ & P-value & $\leq 1 \mathrm{hr}$ & $\geq 4 \mathrm{hr}$ & P-value \\
\hline SVD & 95.1 & 66.3 & $<0.001$ & 91.5 & 45 & $<0.001$ & 95.1 & 37.5 & $<0.001$ \\
\hline $\mathrm{C} / \mathrm{S}$ & 2.2 & 12.3 & $<0.001$ & 2.2 & 18.3 & $<0.001$ & 2.2 & 16.7 & $<0.001$ \\
\hline OVD & 2.7 & 21.4 & $<0.001$ & 4.8 & 36.7 & $<0.001$ & 2.7 & 45.8 & $<0.001$ \\
\hline
\end{tabular}

PPH was more common in mothers whose duration of SSOL was $\geq 3 \mathrm{hr}$ compared to $<1 \mathrm{hr}(13 \%$ vs. $1.8 \%, \mathrm{P}<0.001$, aOR=8.1 and $95 \% \mathrm{CI}$ is $4.2-15.6)$. EBL $>500 \mathrm{ml}$ was significantly associated with operative delivery $(\mathrm{P}<0.001, \mathrm{aOR}=50.99$ and $\mathrm{CI}=30.8-84.2)$ Table
4). It was shown in our study that as the duration of SSOL increased, the presence of composite maternal complication also increased $\mathrm{P}<0.001$. Composite maternal complication was more prevalent in those mothers whose duration of SSOL was $\geq 3 \mathrm{hr}$ compared to $<1 \mathrm{hr}$ 
( $56.9 \%$ vs. $5.7 \%, \mathrm{P}<0.001$, aOR $=19.5$ and $95 \% \mathrm{CI}$ is $12.7-29.8$ ); and $\geq 4 \mathrm{hr}$ compared to $\leq 1 \mathrm{hr}(62.5 \%$ vs. $5.7 \%, \mathrm{P}<0.001$, aOR=24.3 and $95 \% \mathrm{CI}$ is 10.3-57.4). When adjusted for GA, the duration of SSOL after $1 \mathrm{hr}$ showed a significantly strong association with composite maternal complication at any GA $(\mathrm{P}<0.001 \mathrm{l})$ (Table 4).

Table 4: Comparison of maternal outcome with increasing duration of SSOL.

\begin{tabular}{|c|c|c|c|c|c|c|c|c|}
\hline \multirow[t]{2}{*}{ Maternal outcome } & \multirow{2}{*}{$\begin{array}{c}\text { (\%) } \\
\leq 1 \mathrm{hr}\end{array}$} & \multirow{2}{*}{$\begin{array}{c}\text { (\%) } \\
\geq 2 \mathrm{hr}\end{array}$} & \multicolumn{2}{|c|}{ Unadjusted } & \multicolumn{4}{|c|}{ Adjusted } \\
\hline & & & P-value & OR & $95 \% \mathrm{CI}$ & P-value & aOR & 95\%CI \\
\hline $\mathrm{C} / \mathrm{S}$ & 2.2 & 12.3 & $<0.001$ & 6.3 & $4.3-9.2$ & $<0.001$ & 8.0 & $5.4-11.8$ \\
\hline OVD & 2.7 & 21.4 & $<0.001$ & 9.6 & $7.0-13.3$ & $<0.001$ & 9.8 & $7.0-13.7$ \\
\hline Uterine atony & 0.5 & 1.3 & 0.026 & 2.78 & $1.0-7.0$ & 0.021 & 3.1 & $1.1-8.1$ \\
\hline Tear & 0.2 & 0.8 & 0.033 & 3.8 & $1.0-14.2$ & 0.057 & 3.7 & $0.96-14.4$ \\
\hline PPH & 1.8 & 9.2 & $<0.001$ & 5.5 & $3.6-8.4$ & $<0.001$ & 5.6 & $3.6-8.6$ \\
\hline \multirow[t]{2}{*}{ Composite Maternal Complication } & 5.7 & 34.9 & $<0.001$ & $6.9-11.4$ & $<0.001$ & $<0.001$ & 8.3 & $6.4-10.8$ \\
\hline & $\leq 1 \mathrm{hr}$ & $\geq 2 \mathrm{hr}$ & P-value & OR & $95 \% \mathrm{CI}$ & P-value & aOR & 95\%CI \\
\hline $\mathrm{C} / \mathrm{S}$ & 2.2 & 18.3 & $<0.001$ & $5.8-17.7$ & $<0.001$ & 16.4 & 16.4 & $9.0-29.9$ \\
\hline OVD & 2.7 & 36.7 & $<0.001$ & $13.0-32.6$ & $<0.001$ & 23.6 & 23.6 & $14.3-38.8$ \\
\hline Uterine atony & 0.5 & 3.7 & $<0.001$ & 7.7 & $2.4-24.4$ & 0.002 & 7.3 & $2.1-24.9$ \\
\hline Tear & 0.2 & 0.9 & 0.132 & $0.5-39.1$ & 0.142 & 5.3 & 5.3 & $0.5-50$ \\
\hline $\mathrm{PPH}$ & 1.8 & 13.0 & $<0.001$ & 8.0 & $4.2-15.2$ & $<0.001$ & 8.1 & $4.2-15.6$ \\
\hline \multirow[t]{2}{*}{ Composite Maternal Complication } & 5.7 & 56.9 & $<0.001$ & 21.9 & $14.4-33.2$ & $<0.001$ & 19.5 & $12.7-29.8$ \\
\hline & $\leq 1 \mathrm{hr}$ & $\geq 4 \mathrm{hr}$ & P-value & OR & $95 \% \mathrm{CI}$ & P-value & aOR & $95 \% \mathrm{CI}$ \\
\hline $\mathrm{C} / \mathrm{S}$ & 2.2 & 16.7 & $<0.001$ & 9.0 & $2.9-27.4$ & $<0.001$ & 17.8 & $5.2-60.8$ \\
\hline OVD & 2.7 & 45.8 & $<0.001$ & 30.1 & $13.0-69.6$ & $<0.001$ & 35.2 & $13.7-90.4$ \\
\hline Uterine atony & 0.5 & 8.3 & $<0.001$ & 18.4 & $3.9-87.5$ & 0.002 & 15.0 & $2.7-81.8$ \\
\hline Tear & 0.2 & 4.2 & $<0.001$ & 21.2 & $2.3-189.3$ & 0.006 & 26.5 & $2.5-276$ \\
\hline $\mathrm{PPH}$ & 1.8 & 12.5 & $<0.001$ & 7.75 & $2.23-26.9$ & 0.002 & 7.3 & $2.0-26.2$ \\
\hline Composite Maternal Complication & 5.7 & 62.5 & $<0.001$ & 27.7 & $11.9-64.4$ & $<0.001$ & 24.3 & $10.3-57.4$ \\
\hline
\end{tabular}

\section{Discussion}

Analgesia and anaesthesia have occupied a pivotal role in the practice of modern obstetrics. There has always been a well adhered dictum that it is divine to abolish pain in labour in particular and especially during the second stage of labour. Epidural anaesthesia in labour in a low resource setting may be a farfetched well intended phenomenon but a clear distinction between the haves and havenots. None of the women in our study had epidural anaesthesia and all the comparisons are based and made on the conventional rules despite lack of uniform and strict definition of duration and treatment of second stage of labor $[2,20,21]$. The mean duration of SSOL found in the current study, $62 \mathrm{~min}$ with a range 4 to 330 minutes is approximately comparable with the study done that showed the mean duration of the second stage of labour to be 70min (range 2-387, SD +73min) [20].

Concerning the nullipara, the mean duration of SSOL was $69.4 \min \pm 47.4$ (5-330) $\mathrm{min}$. This is much shorter when compared to the most recent study done by Sandström which stated that, the median duration of second stage of labour was 93 min and $95 \%$ were delivered within $272 \min (4.5 \mathrm{~h}$ ) [22]. This variation could partly be explained by the difference in the studied population and the local policy and guidelines of the management of labour. It was also observed that only $15.8 \%$ of the mothers in this study delivered within 30 minuts, $55.8 \%$ within an hour and $86.3 \%$ within 2hours after they reached SSOL. This is contrary to the study done by Duignan which states that even $83 \%$ of the primiparas gave birth within an hour and $98.5 \%$ of multipara delivered with in 2 hour [23]. Nevertheless, it is similar to Friedman's study which evaluated the natural course of labour and noted that most nulliparous women without epidural anesthesia delivered within 2 hours [2,3].

In our study, only $2.9 \%$ of the labouring mothers stayed for more than 3 hours in SSOL. This is in contrast to the publication by Allen et al. where it is stated that $14.8 \%$ of nulliparous women were identified as having a second stage of labour duration longer than 3 hours and $3.2 \%$ of multiparous women were identified as having a second stage of labour duration of longer than 2 hours [24]. We have also observed that as maternal age and parity increases duration of SSOL significantly decreases. This is also true for most of the 
studies done previously $[12,19,23]$. As shown in our study, EBL had a statistically significant association with duration of SSOL. PPH is more common in those mothers whose duration of SSOL is $\geq 2 \mathrm{hr}$ compared to $\leq 1 \mathrm{hr} 9.2 \%$ vs. $1.8 \%$. This association is also seen in another study that showed that there is slight increase in PPH after duration of SSOL is extended beyond 2 hours, but the association is more significant after the duration of SSOL is more than 3 hours [25]. Our finding showed that increased blood loss is more common among mothers delivered by operative means compared to SVD at any time; and other studies also reported the same [24].

The actual rate of SVD of $95.4 \%, 45 \%$ and $37.5 \%$ decline as a factor of time is well substantiated as duration of SSOL increased from $<1 \mathrm{hr}$, $>3 \mathrm{hr}$ and $>4$ hours, respectively. This is comparable with the study done by Rouse etal, which calculated the SVD rate to be $85 \%$ when the duration was 1 hour to $24.2 \%$ when the duration of SSOL is $>3 \mathrm{hr}$ and $9 \%$ when it was 5 hours [12]. However, the rate of vaginal delivery is much higher than the study done by YuehChang Kuo and colleagues which showed spontaneous vaginal delivery occurring in $82.3 \%$ of patients with a normal second stage $(<120 \mathrm{~min})$, and $33.2 \%$ of patients with a prolonged second stage of $\geq 120$ min [19].

Contrary to this, caesarean section rate progressively increased from $2.2 \%$ when duration SSOL is $<1 \mathrm{hr}$ to $18.3 \%$ when duration of SSOL is $\geq 3 \mathrm{hr}$ and $16.7 \%$ when duration of SSOL is $\geq 4 \mathrm{hr}$. According to Rouse et.al caesarean section rate with duration of SSOL is almost comparable to our study upto $3 \mathrm{hr}$ but after that it is much higher; caesarean section rate is $1.4 \%$ when duration of SSOL is $<1 \mathrm{hr}$ but it is $38.3 \%$ when duration of SSOL is $\geq 3 \mathrm{hr}$ and $47.4 \%$ when duration of SSOL is $\geq 4 \mathrm{hr}$ [12]. Operative vaginal delivery rate also increased with increasing duration of SSOL, from $2.7 \%$ when the duration was $\leq 1 \mathrm{hr}$ to $36.7 \%$ when duration of SSOL was $\geq 3 \mathrm{hr}$. comparable result is also seen on the Rouse DJ et al study which showed OVD rate of $34.6 \%$ when duration of SSOL is $>3 \mathrm{hr}$ [12]. But the result is much different from the study done in Taiwan which showed a higher rate of instrumental vaginal delivery, that is $17.7 \%$ within a normal second stage $(<120 \mathrm{~min})$ and $66.7 \%$ within a prolonged second stage ( $\geq 120 \mathrm{~min})$ [19].

Major degree tear is significantly associated with duration of SSOL when duration of SSOL $\geq 2 \mathrm{hr}$ compared to $\leq 1 \mathrm{hr}(0.8 \%$ vs. $0.2 \%$ ). However, when adjusted for possible confounder the significance was lost for this comparison. When we compare duration of SSOL $\geq 4 \mathrm{hr}$ to $\leq 1 \mathrm{hr}$ for major degree tear it is significantly higher even after adjusting for confounders (4.2 vs. $0.2, \mathrm{P}=0.006$ aOR=26.5, 95\%CI 2.5-276). This figure is different from study done by the Rouse DJ et. al which showed that major degree tear is 23.5\% in those mothers who stayed in SSOL for more than 4 hours [12]. The study in Munich showed higher results; patients with a prolonged second stage of labour sustained such a tear significantly more often $(7.7 \%)$ than patients with a normal duration of second stage (2.9\%). The highest incidence of these tears was observed in patients with duration of the second stage longer than $4 \mathrm{hr}(12.8 \%)$.
Patients with a vaginal operative delivery suffered significantly more often from a third-degree sphincter tear (9.3\%) than patients with a spontaneous delivery $2.9 \%$ [20]. Unlike the setups in the more advanced countries where there exist the personnel, the finance, the infrastructure, logistics including medicines and gadgets like fetal electrocardiography, cardiotocography, strict policies in implementing partographs and rules and regulations in place pertaining to one-to-one follow up and monitoring during labour that obviously highlight the differences and accentuates the reasons for undertaking such a study. This study will generate evidence on effect of duration of second stage on maternal outcome in our setup that would serve as future building blocks.

\section{Acknowledgment}

Our deepest thankfulness is extended to the Department of Gynaecology and Obstetrics, Addis Ababa University, the medical directors of the four corresponding hospitals, the data collectors and supervisors as well as to those who have directly or indirectly contributed and supported throughout the study and preparation of the manuscript.

\section{References}

1. Hellman LM, Prystowsky H (1952) The duration of the second stage of labor. Am J Obstet Gynecol 63(6): 1223-1233.

2. Friedman EA (1954) The graphic analysis of labor. Am J Obstet Gynecol 68(6): 691-703.

3. Friedman EA (1955) Primigravid labor: A graphicostatistical analysis. Obstet Gynecol 6(7): 567-589.

4. Laughon K, Berghella V, Reddy Uma M, Sundaram R, Zhaohui Lu, et al. (2014) Neonatal and Maternal Outcomes with Prolonged Second Stage of Labor. The American College of Obstetricians and Gynecologists 124(1): 57-67.

5. (2018) WHO Reproductive Health Library. WHO recommendation on definition and duration of the second stage of labour (February 2018). The WHO Reproductive Health Library; Geneva: World Health Organization.

6. Saunders NS, Paterson CM, Wadsworth J (1992) Neonatal and maternal morbidity in relation to the length of the second stage of labour. $\mathrm{Br} \mathrm{J}$ Obstet Gynaecol 99(5): 381-385.

7. Myles TD, Santolaya J (2003) Maternal and neonatal outcomes in patients with a prolonged second stage of labor. Obstet Gynecol 102(1): 52-58.

8. Leveno KJ, Nelson DB, McIntire DD (2016) Second stage labor: How long is too long? Am J Obstet Gynecol 214(4): 484-489.

9. Allen VM, Baskett TF, O'Connell CM, McKeen D, Allen AC (2009) Maternal and perinatal outcomes with increasing duration of the second stage of labor. Obstet Gynecol 113(6): 1248-1258.

10. Hunt CJ, Menticoglou M (2015) Perinatal Outcome in 1515 Cases of Prolonged Second Stage of Labour in Nulliparous Women. J ObstetGynaecol Can 37(6): 508-516.

11. Altman MR, Mona T Lydon Rochelle (2006) Prolonged Second Stage of Labor and Risk of Adverse Maternal and Perinatal Outcomes: A Systematic Review. BIRTH 33(4): 315-322.

12. Rouse DJ WS, Bloom SL (2009) Second-stage labor duration in nulliparous women: relationship to maternal and perinatal outcomes. Am J Obstet Gynecol 201(4): 357.

13. Bleich ATT, Alexander JMM, McIntire DDD, Leveno KJ (2012) An analysis of second-stage labour beyond $3 \mathrm{~h}$ in nulliparous women. Am J Perinatol 29(9): 717-722. 
14. Caughey AB (2009) Is there an upper time limit for the management of the second stage of labor? Am J Obstet Gynecol 201(4): 337-338.

15. Cheng Y, Hopkins L, Laros J, Caughey A (2007) Duration of the second stage of labor in multiparous women: maternal and neonatal outcomes. Am J ObstetGynecol 196(6): 585.e1-6.

16. FIGO Safe Motherhood and Newborn Health (SMNH) Committee (2012) Management of the of labor. International Journal of Gynaecology and Obstetrics 119(2): 111-116.

17. Savas M, Menticoglou M, Frank Manning M, Christopher Harman M, Ian Morrison M (1995) Perinatal outcome in relation to second-stage duration. Am J Obstet Gynecol 173(3 Pt 1): 906-912.

18. Jos B Delee M (1920) The prophylactic forceps operation. Am J obstetGynecol 1(1): 34-44.

19. Yueh Chang KuoC PC, Kuo Gon Wang (1996) Factors Influencing the Prolonged Second Stage and the Effects on Perinatal and Maternal Outcomes. J ObstetGynaecol 22(3): 253-257.

20. Janni W, Schiessl B, Peschers U, Huber S, Strobl B, et al. (2002) The prognostic impact of a prolonged second stage of labor on maternal and fetal outcome. Acta Obstet Gynecol Scand 81(3): 214-221.

ISSN: 2574-1241

DOI: 10.26717/BJSTR.2019.22.003683

Lukman Yusuf. Biomed J Sci \& Tech Res

This work is licensed under Creative Commons Attribution 4.0 License

Submission Link: https://biomedres.us/submit-manuscript.php
21. Fraser WD, Marcoux S, Krauss I, Douglas J, Goulet C, et al. (2000) Multicenter, randomized, controlled trial of delayed pushing for nulliparous women in the second stage of labor with continuous epidural analgesia. The PEOPLE (Pushing Early or Pushing Late with Epidural) Study Group. Am J ObstetGynecol 182(5): 1165-1172.

22. Sandström A, Cnattingius S, Johansson S, Stephansson O, Altman M, et al. (2017) Durations of second stage of labor and pushing, and adverse neonatal outcomes: a population-based cohort study. Journal of Perinatology 37(3): 236-242.

23. Duignan NM, Studd JWW, Hughes A (1975) Characterstics of normal labour in different racial groups. British Journal of Obstetrics and Gynaecology 82(8): 591-601.

24. Cheng YW, Hopkins LM, Caughey AB (2004) How long is too long: Does a prolonged second stage of labourv in nulliparous women affect maternal and neonatal outcomes? Am. J Obstet Gynecol 191(3): 933-938.

25. Cohen WR (1977) Influence of the duration of second stage labor on perinatal outcome and puerperal morbidity. Obstet Gynecol 49(3): 266269.

\begin{tabular}{ll}
\hline & Assets of Publishing with us \\
\hline $\begin{array}{l}\text { BIOMEDICAL } \\
\text { - Global archiving of articles }\end{array}$ & Immediate, unrestricted online access \\
\hline
\end{tabular}

